\title{
Electrophysiological appraisal of relative segmental motoneurone pool excitability in flexor and extensor muscles
}

\author{
MOR R IS A. FISHER \\ From the Department of Neurological Sciences and the Laboratory of Clinical Neurophysiology, \\ Rush-Presbyterian-St Luke's Medical Center, Chicago, Illinois, USA
}

SUMMARY F responses recorded from flexor and extensor muscles were analysed in 18 normal subjects and in 16 patients with motor system abnormalities. The prominence of the $F$ responses was evaluated quantitatively by determining the persistence-that is, the fraction of measurable $F$ responses which actually occur after a series of supramaximal stimuli-and average amplitude of the $\mathrm{F}$ responses. In the normal resting state, the data are consistent with the hypothesis that the "central excitatory states" of motoneurones is greater in the antigravity muscles than in those muscles not stretched by gravity. This pattern was disrupted in eight of the 16 patients with motor system abnormalities caused by central nervous system lesions. These changes reflect a clinically testable aspect of the pathophysiology of certain motor system disorders.

Successful therapy for motor system abnormalities may depend on the ability of the clinical neurophysiologist to provide more specific definitions of these disorders. Serious criticism of the use of broad terms such as "spasticity" or "rigidity" has been made for a generation (Meyers, 1953) and has continued to the present (Landau, 1974). Ultimately motor abnormalities must reflect altered firing of motoneurones. Clinically useful measurements of motoneurone excitability would be important for our understanding of motor system dysfunction. The potential of the $F$ response for providing a quantitative measure of segmental motoneurone pool excitability has been demonstrated (Fisher et al., 1976, 1978).

Electrophysiological criteria for the $F$ response have been published (Shahani and Young, 1976). Originally described by Magladery and McDougal (1950), this action potential response of a muscle is found readily in a wide distribution when its motor nerve is stimulated supramaximally. It is a response of low amplitude, usually less than 5\% of the direct motor (M) response, with a latency directly related to the distance of the stimulating

Address for reprint requests: Dr M. A. Fisher, Department of Neurological Sciences, EMG Laboratory, Rush-Presbyterian-St Luke's Medical Center, 1753 West Congress Parkway, Chicago, Illinois 60612, USA.

Accepted 1 February 1978 and recording sites from the spinal cord. Characteristically, the amplitude, latency, and configuration of the $F$ response fluctuate with each stimulus. As an $F$ response may be found in the absence of afferent input in both animals (Gassel and? Wiesandanger, 1965; McLeod and Wray, 1966) and man (Mayer and Feldman, 1967; Miglietta, 1973), the response is thought to reflect antidromic activation of motoneurones. Single fibre studies (Trontelj, 1973) have confirmed the presence of this activation.

It is the purpose of this report to show an extension of the usefulness of the $F$ response for understanding motor system abnormalities. In particular, the prominence of the $F$ response in flexor and extensor muscles follows a reproducible pattern which is altered by lesions of the central nervous system.

\section{Subjects and methods}

A series of $F$ responses was performed on 18 volunteer subjects without any neurological abnormality. The ages ranged from 22 to 39 years with an average age of 28 years. Similar studies were performed on 16 patients (average age 34 years, range 6-65 years). These patients were unselected except for their referral to the EMG laboratory for electrodiagnostic evaluation. The 
basis for their motor system dysfunction was diverse. All of the 16 patients had weakness and/ or abnormalities of movement associated with at least increased tone (12), increased deep tendon reflexes (12), or a Babinski response (6).

The $F$ responses were recorded from the following muscles: the abductor hallucis (AH), extensor digitorum brevis (EDB), medial aspect of the soleus (MS), tibialis anterior (TA), abductor pollicis brevis (APB), and extensor digitorum communis (EDC). The TA/MS and EDB/AH are pairs of physiological flexor/extensor muscles acting at the same joint. This classification for the TA, MS, and EDB is consistent with Sherrington's (1910) classical work. As the AH acts in a reciprocal fashion to the EDB (Kugelberg et al., 1960), the AH has been classified as a physiological extensor. Comparable recordings in the upper extremity are more difficult since the muscles are closer to the spinal cord. The $F$ response latencies are comparably shorter and thus more readily obscured by the direct motor (M) responses. The APB and EDC were chosen as technically feasible muscles which were classified as physiological flexors and extensors by analogy with the role of comparable muscles in the lower extremity, taking account of the altered relation of the upper extremity to gravity.

During the studies, the subjects lay comfortably in a supine position. Surface disc electrodes were used throughout. Belly-tendon recordings were made in the standard manner from the AH, EDB, and APB. Recordings were made from the bellies of the TA, MS, and EDC with the electrodes $50 \mathrm{~mm}$ apart. The active electrode was proximal and was placed halfway between the tibial tubercle and the ankle joint for the TA, halfway between the mid-popliteal crease and the medial malleolus for the MS, and halfway between the olecranon and the radial styloid for the EDC. The stimulus was given to the peroneal nerve at the ankle when recording from the EDB; to the posterior tibial nerve in the region of the medial malleolus for the $\mathrm{AH}$; and the posterior tibial in the popliteal fossa, the peroneal nerve at the fibular head, the median nerve at the wrist, and the radial nerve in the lower third of the forearm for the MS, TA, APB, and EDC respectively. The stimulus was given using a bipolar surface electrode with a fixed electrode separation of $30 \mathrm{~mm}$ (TECA 60301) with the cathode distal. The stimulus frequency was $0.5 \mathrm{~Hz}$. The stimulator (TECA NS6) voltage (maximum 300 volts) and duration (range 0.05 to $1 \mathrm{~ms}$ ) were adjusted to produce a stimulus intensity $25 \%$ supramaximal for the $M$ response. Care was taken to use as brief a duration as poss- ible in order to minimise any discomfort. In general, a duration of $0.1 \mathrm{~ms}$ combined with a voltage in the range of $200-300 \mathrm{~V}$ has been found adequate.

At least 10 responses were recorded from each muscle. Persistence and average $F$ amplitude (measured peak-to-peak) were calculated. As an $F$ response may not appear after every stimulus, persistence refers to the number of measurable $F$ responses divided by the number of supramaximal stimuli. Using the methods of this study, an $F$ response with an amplitude of less than $20 \mu \mathrm{V}$ could not be measured with certainty and was considered absent. The average $F$ amplitude was not calculated for a particular muscle unless at least five measurable $F$ responses were obtained from the muscle.

The procedures in this work are, of course, routine electrophysiological studies. They are entirely harmless and well tolerated. Informed permission was obtained from the volunteers. Eight patients with severe motor system abnormalities were studied as part of their routine evaluation before the implantation of cerebellar electrodes (Fisher and Penn, 1978). The remaining patients were referred by their physicians for electrophysiological evaluation and were fully informed as to the nature of the studies to be performed.

\section{Results}

\section{NORMAL SUBJECTS}

The average size and persistence of an $F$ response varies in a reproducible way in normal individuals. These data are shown in Table 1 for the muscles examined in lower and upper extremities. There were no significant differences between the right and left sides. The information from both sides is combined and presented in Figs. 1 and 2 to emphasise the prominent differences in the muscles tested. Representative $F$ responses are shown in Fig. 3.

The relative prominence of the $\mathrm{F}$ response in the muscles tested is true not only if we analyse the data as a whole (as above), but also if we examine the data obtained from each individual subject. In only three of 82 sets of $F$ responses recorded from either the right or left EDB, TA, or EDC was the $F$ persistence greater than that found in similar studies from the AH, MS, or APB respectively. The data for average F amplitudes are presented in Table 2 . This shows that the maximum average $F$ amplitudes ratio for TA/MS, $\mathrm{EDB} / \mathrm{AH}$, and EDC/APB was 1.05 and that the means for these ratios were all clearly less than one. 
Table $1 F$ responses amplitude, latency, and persistence

\begin{tabular}{|c|c|c|c|c|c|c|c|}
\hline \multirow[t]{2}{*}{ F response } & & \multicolumn{6}{|l|}{ Muscle 1} \\
\hline & & $M S$ & $T A$ & $A H$ & $E D B$ & $A P B$ & $E D C$ \\
\hline \multicolumn{8}{|c|}{ Average amplitude $(\mu \mathrm{V})$} \\
\hline \multirow{2}{*}{$\mathbf{N}$} & $\mathbf{R}$ & 16 & 6 & 15 & 10 & 18 & 5 \\
\hline & $\mathbf{L}$ & 16 & 6 & 16 & 7 & 17 & 7 \\
\hline \multirow[t]{2}{*}{ mean $\pm S D$} & $\mathbf{R}$ & $370 \pm 169$ & $143 \pm 98$ & $401 \pm 123$ & $232 \pm 101$ & $350 \pm 129$ & $184 \pm 50$ \\
\hline & L & $350 \pm 120$ & $165 \pm 60$ & $374 \pm 130$ & $251 \pm 112$ & $354 \pm 98$ & $154 \pm 45$ \\
\hline \multirow[t]{2}{*}{ range } & $\mathbf{R}$ & $158-700$ & $57-285$ & $204-604$ & $120-467$ & $175-618$ & $125-242$ \\
\hline & $\mathbf{L}$ & $231-517$ & $100-271$ & $213-650$ & $129-464$ & $188-554$ & $100-210$ \\
\hline \multicolumn{8}{|l|}{ Latency (ms) } \\
\hline \multirow[t]{2}{*}{$\mathbf{N}$} & $\mathbf{R}$ & 16 & 6 & 15 & 10 & 18 & 5 \\
\hline & $\mathbf{L}$ & 16 & 6 & 16 & 7 & 17 & 7 \\
\hline \multirow[t]{2}{*}{ mean $\pm \mathbf{S D}$} & $\mathbf{R}$ & $30.2 \pm 2.7$ & $30.1 \pm 3.0$ & $48.2 \pm 4.7$ & $46.7 \pm 4.4$ & $25.9 \pm 1.6$ & $20.1 \pm 1.8$ \\
\hline & $\mathbf{L}$ & $30.5 \pm 2.3$ & $29.8 \pm 5.0$ & $48.9 \pm 4.9$ & $45.4 \pm 5.5$ & $25.9 \pm 1.9$ & $20.6 \pm 2.2$ \\
\hline \multirow[t]{2}{*}{ range } & $\mathbf{R}$ & $26.2-35.3$ & $24.6-33.0$ & $40.2-54.6$ & $40.0-52.1$ & 22.4-28.2 & $18.1-22.5$ \\
\hline & $\mathbf{L}$ & $27.0-35.3$ & $22.9-34.7$ & $40.5-56.0$ & $40.3-52.7$ & $22.8-28.4$ & $18.0-23.9$ \\
\hline \multirow{3}{*}{$\begin{array}{l}\text { Persistence } \\
\text { N }\end{array}$} & & & & & & & \\
\hline & $\mathbf{R}$ & 16 & 15 & 15 & 15 & 18 & 12 \\
\hline & $\mathbf{L}$ & 16 & 15 & 16 & 14 & 17 & 12 \\
\hline \multirow[t]{2}{*}{ mean } & $\mathbf{R}$ & 0.86 & 0.32 & 1.00 & 0.38 & 0.81 & 0.29 \\
\hline & L & 0.83 & 0.33 & 0.93 & 0.35 & 0.84 & 0.26 \\
\hline \multirow{2}{*}{ range } & $\mathbf{R}$ & $0.75-1.00$ & $0.00-1.00$ & $(1.00)$ & $0.00-0.80$ & $0.60-1.00$ & $0.00-1.00$ \\
\hline & $\mathbf{L}$ & $0.75-1.00$ & $0.00-1.00$ & $0.62-1.00$ & $0.00-0.75$ & $0.60-1.00$ & $0.00-1.00$ \\
\hline
\end{tabular}

$R=$ right $; \mathrm{L}=$ left $\mathbf{N}=$ number of observations; $\mathbf{S D}=$ standard deviation.

${ }_{1}$ For key see Methods.

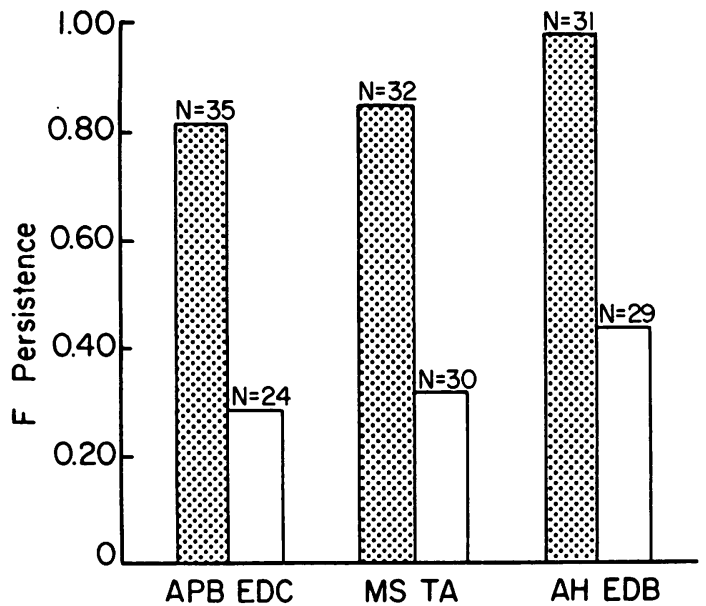

Fig. 1 Representative $F$ responses recorded from the tibialis anterior $(T A)$ and soleus $(M S)$ muscles before $(A)$ and after $(B)$ the start of cerebellar stimulation. Calibration $500 \mu \mathrm{V}$ and $10 \mathrm{~ms}$.

\section{PATIENTS}

In contrast to the findings in the normal subjects, eight of the 16 patients studied had at least one $\mathrm{TA} / \mathrm{MS}$ or EDB/AH F amplitude ratio of 1.5 or greater (range 1.6 to 5.1) - that is, a ratio significantly greater than that found in any of the control studies. In those two patients in whom the motor abnormalities were unilateral, the abnormal $F$ response studies were only on the affected side; and, in one patient with motor findings clearly predominant on one side, the $F$ response studies

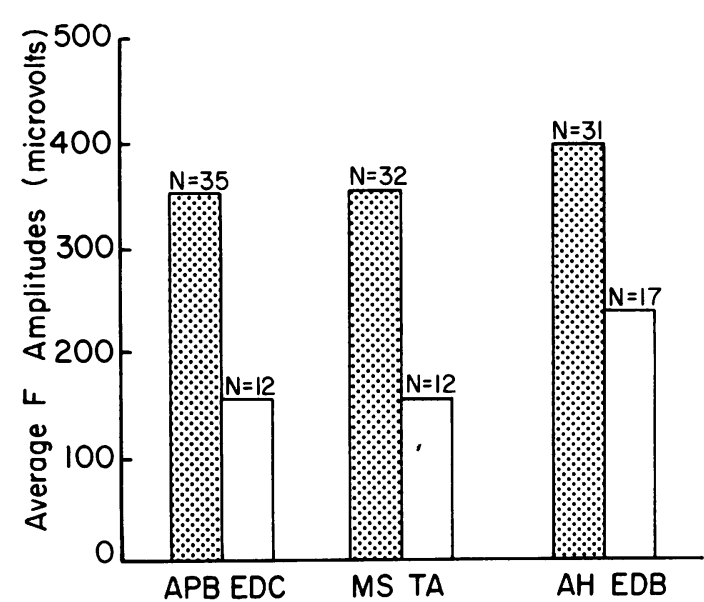

Fig. 2 Means of the average $F$ amplitudes in the muscles studied in which at least five measurable $F$ responses were obtained.

were abnormal only on that side. In the two patients in whom $F$ response amplitude flexor/ extensor ratios were abnormal bilaterally, the clinical abnormalities were equal on both sides. In the remaining three patients with bilateral clinical findings and unilateral abnormalities of $F$ response ratios, the tone and/or deep tendon reflexes were increased on the side of the abnormal $F$ responses.

Normal $F$ amplitude ratios were present in one patient with "spasticity" characterised by increased tone in antigravity muscles, increased phasic stretch reflexes, and abnormal presence of 

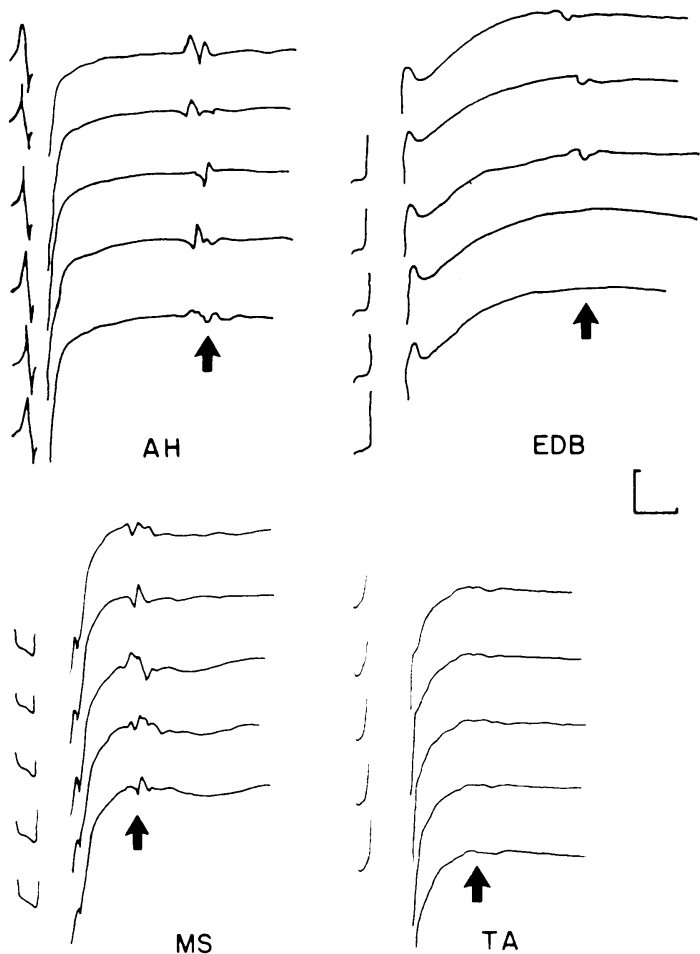

Fig. 3 Representative $F$ responses from the muscles studied in the lower extremity. The $F$ responses are more prominent in the $A H$ and $M S$ compared with the $E D B$ and $T A$ respectively. Calibration $500 \mu V$ and $10 \mathrm{~ms}$.

Table 2 F amplitude ratios

\begin{tabular}{llll}
\hline \multicolumn{4}{c}{ Muscles } \\
& EDC/APB & $T A / M S$ & $E D B / A H$ \\
\cline { 2 - 4 } & & 12 & 16 \\
Number of observations & 12 & 0.47 & 0.57 \\
Mean & 0.49 & $0.16-0.95$ & $0.24-1.05$ \\
Range & $0.17-0.093$ & & \\
\hline
\end{tabular}

H reflexes (Magladery et al., 1952; Thorne, 1965; Garcia-Mullin and Mayer, 1972). Three patients with motor and sensory abnormalities caused by spinal cord lesions were studied. All three of these patients had abnormal $F$ amplitude ratios. (The lesions were all above the segmental level of the $F$ response abnormalities.) Of the remaining five patients with abnormal $F$ responses, four had clinical findings usually considered to be indicators of "cerebellar" or "basal ganglionic" dysfunction, that is, dysmetria, athetosis, and/or dystonia.

No obvious distinction could be made between those patients with or without abnormal $F$ response ratios and increase in phasic stretch reflexes, Babinski responses, increase in tone, or sensory loss. In the eight patients with abnormal $F$ response ratios, seven had increased phasic stretch reflexes, three Babinski responses, five increase in tone, and three sensory abnormalities. Comparable numbers for the eight patients with normal $F$ response ratios were $5,3,3$, and 2 respectively.

\section{Discussion}

This work demonstrates that the prominence of the $F$ response follows a reproducible pattern. The data are consistent with the hypothesis that the differences relate to the physiological role of a muscle, and in particular, that in the normal, resting state $F$ responses are more prominent in antigravity muscles than in those muscles not stretched by gravity. This is certainly reasonable for those muscles tested in the lower extremity. The data from the upper extremity are consistent but less conclusive as the muscles tested do not act at the same joint and the physiological role of the APB needs further definition. Nevertheless, the $F$ response from the EDC is clearly not prominent. The $H$ reflexes can be obtained routinely in the superficial forearm flexors (Deschuytere et al., 1976) which suggests that these muscles have physiological similarities to the comparable extensor muscles in the leg. By analogy, it seems reasonable that the EDC should have physiological features similar to the corresponding leg flexors.

I believe that the differences in the $\mathrm{F}$ response reflect differences in motoneurone pool excitability. It is recognised that the basis for the variability in the $F$ response (not only between muscles but with each stimulus) is complex, involving segmental and suprasegmental mechanisms. In addition, the responses analysed may not be an entirely homogeneous group. The response from the $\mathrm{AH}$, for example, tends to be of unusually long duration, unusually polyphasic, and unusually persistent. Indeed, as in cats, the $\mathrm{F}$ response from the AH may be partially a polysynaptic reflex (Gassel and Wiesandanger, 1965). Nevertheless, as has been mentioned, $F$ responses are present in the absence of afferent input. In these circumstances, they must reflect antidromic activation of motoneurones, and there is no evidence to suggest that, even in the intact individual, $F$ responses do not reflect motoneurone pool excitability. Given these considerations, it seems reasonable to conclude that the "central excitatory state" 
of motoneurone pools is normally relatively greater in antigravity muscles. As this should reflect a fundamental aspect of motor system organisation, it is not surprising that this relation can be disrupted in lesions of the central nervous system.

The relative excitability states of flexor and extensor motoneurone pools must depend partially on segmental reflex mechanisms, and disturbance of these reflex patterns must be a feature of motor system abnormalities. Lundberg and Voorhoeve (1962) have demonstrated in cats that pyramidal tract stimulation can facilitate reflex paths mediated by Ia, Ib, flexor reflex, and cutaneous afferent nerve fibres. Corticospinal tract injury could in theory produce either a depression or excitation of these reflexes. A pattern of decrease and then increase in, at least, phasic and tonic stretch reflexes is a common clinical feature of many central nervous system lesions. "Extrapyramidal" disorders classically have different clinical features and presumably different pathophysiological features. It would not be surprising if this involved a more discernible distortion of the normal relative excitability between flexor and extensor muscles. "Reciprocal change in antagonistic muscle groups is characteristic of movements elicited from the cortex of the cerebellum as well as its nuclei" (Henneman, 1974), and there is evidence consistent with abnormal segmental reflex excitability between flexor and extensor muscles in patients with Parkinson's disease (Bathien and Rondot, 1977). It is, therefore, of interest that in this series of patients clinical features of "spasticity" per se were not associated with abnormality of $F$ amplitude flexor/extensor ratios, while four of the five patients with such abnormalities and supraspinal lesions had clinical dysfunction consistent with "extrapyramidal" lesions.

Thanks are given to Ms Barbara Karakusis for her technical assistance.

\section{References}

Bathien, N., and Rondot, P. (1977). Reciprocal continuous inhibition in rigidity of Parkinsonism. Journal of Neurology, Neurocurgery, and Psychiatry, 40, 20-24.

Deschuytere, J., Roselle, N., and de Keyser, C. (1976). Monosynaptic reflexes in the superficial forearm flexors in man and their clinical significance. Journal of Neurology, Neurosurgery, and Psychiatry, 39, 555-565.

Fisher, M. A., and Penn, R. D. (1978). Evidence for changes in segmental motoneurone pools by chronic cerebellar stimulation and its clinical significance.
Journal of Neurology, Neurosurgery, and Psychiatry, 41, 630-635.

Fisher, M. A., Shahani, B. T., and Young, R. R. (1976). Quantitative assessment of excitability at segmental levels of the central nervous system caudal to acute lesions. Neurology (Minneapolis), 26, 366-367.

Fisher, M. A., Shahani, B. T., and Young, R. R. (1978). Quantitative assessment of excitability at segmental levels of the CNS following acute rostral lesions. I Study of the $\mathrm{F}$ response. Neurology (Minneapolis). In press.

Garcia-Mullin, R., and Mayer, R. F. (1972). H reflexes in acute and chronic hemiplegia. Brain, 95, 559-572.

Gassel, M. M., and Wiesandanger, M. (1965). Recurrent and reflex discharges in plantar muscles of the cat. Acta Physiologica Scandinavica, 65, 138142.

Henneman, E. (1974). The cerebellum. In Medical Physiology. Vol. 1, p. 734. Edited by V. B. Mountcastle. C. V. Mosby: St. Louis.

Kugelberg, E., Eklund, K., and Grimby, L. (1960). An electromyographic study of the nociceptive reflexes of the lower limb. Mechanism of the plantar re'ponses. Brain, 83, 394-410.

Landau, W. M. (1974). Spasticity: the fable of a neurological demon and the emperor's new therapy. Archives of Neurology (Chicago), 31, 217-219.

Lundberg, A., and Voorhoeve, P. (1962). Effects from the pyramidal tract on spinal reflex arcs. Acta Physiologica Scandinavica, 56, 201-219.

Magladery, J. W., and McDougal, D. B. (1950). Electrophysiological studies of nerve and reflex activity in normal man. 1. Identification of certain reflexes in the electromyogram and the conduction velocity of peripheral nerve fibers. Bulletin of the Johns Hopkins Hospital, 86, 265-290.

Magladery, J. W., Porter, W. E., Park, A., and Languth, H. W. (1952). Electrophysiological studies of reflex activity in patients with lesions of the nervous system. II. Disclosure of normally suppressed monosynaptic reflex discharge of spinal motoneurones by lesions of lower brain-stem and spinal cord. Bulletin of the Johns Hopkins Hospital, 91, 245-256.

Mayer, R. F., and Feldman, R. G. (1967). Observation on the nature of the $F$ wave in man. Neurology (Minneapolis), 17, 147-156.

McLeod, J. G., and Wray, S. H. (1966). An experimental study of the $\mathrm{F}$ wave in the baboon. Journal of Neurology, Neurosurgery, and Psychiatry, 29, 196-200.

Meyers, R. (1953). The extrapyramidal system: an inquiry into the validity of the concept. Neurology (Minneapolis), 3, 627-655.

Miglietta, O. E. (1973). The F response after transverse myelotomy. In New Developments in Electromyography and Clinical Neurophysiology. Vol. 3, pp. 323-327. Edited by J. E. Desmedt. Karger: Basel.

Shahani, B. T., and Young, R. R. (1976). Effect of 
vibration on the $\mathrm{F}$ response. In The Motor system: Neurophysiology and Muscle Mechanisms. Pp. 189195. Edited by M. Shahani. Elsevier: Amsterdam.

Sherrington, C. S., (1910). Flexion-reflex of the limb, crossed extension reflex, and reflex stepping and standing. Journal of Physiology, 40, 28-121.

Thorne, J., (1965). Central responses to electrical activation of the peripheral nerves supplying the intrinsic hand muscles. Journal of Neurology, Neurosurgery, and Psychiatry, 28, 482-495.

Trontelj, J. V., (1973). A study of the $F$ response by single fiber electromyography. In New Developments in Electromyography and Clinical Neurophysiology. Vol. 3, pp. 318-322. Edited by J. E. Desmedt. Karger: Basel. 